\title{
Variable flocculation profiles of yeast strains isolated from cachaça distilleries
}

\author{
Florencia Alvarez ${ }^{\mathrm{b}, 1}$, Lygia Fátima da Mata Correa ${ }^{\mathrm{a}, 1}$, Thalita Macedo Araújo a , Bruno Eduardo Fernandes Mota ${ }^{\mathrm{a}}$, \\ Luís Eduardo F. Ribeiro da Conceição ${ }^{a}$, Ieso de Miranda Castro a , Rogelio Lopes Brandão ${ }^{a}, *$ \\ a Laboratório de Biologia Celular e Molecular, Núcleo de Pesquisas em Ciências Biológicas, Universidade Federal de Ouro Preto, Brazil \\ b Cerlev - Projetos e Inovação na Biotecnologia da Fermentação Ltda, Rua Amaro Lanari 59, Saramenha, 35.400-000 Ouro Preto, MG, Brazil
}

\section{A R T I C L E I N F O}

Article history:

Received 7 April 2014

Received in revised form 4 August 2014

Accepted 9 August 2014

Available online 21 August 2014

\section{Keywords:}

Saccharomyces cerevisiae

Flocculation

Ale and lager behaviors

Cachaça

\begin{abstract}
A B S T R A C T
In cachaça production, the use of yeast cells as starters with predictable flocculation behavior facilitates the cell recovery at the end of each fermentation cycle. Therefore, the aim of this work was to explain the behavior of cachaça yeast strains in fermentation vats containing sugarcane through the determination of biochemical and molecular parameters associated with flocculation phenotypes. By analyzing thirteen cachaça yeast strains isolated from different distilleries, our results demonstrated that neither classic biochemical measurements (e.g., percentage of flocculation, EDTA sensitivity, cell surface hydrophobicity, and sugar residues on the cell wall) nor modern molecular approaches, such as polymerase chain reaction (PCR) and real-time PCR (q-PCR), were sufficient to distinctly classify the cachaça yeast strains according to their flocculation behavior. It seems that flocculation is indeed a strain-specific phenomenon that is difficult to explain and/or categorize by the available methodologies.
\end{abstract}

(c) 2014 Published by Elsevier B.V.

\section{Introduction}

Yeast flocculation is the asexual, calcium-dependent, and reversible aggregation of cells into flocs with subsequent rapid sedimentation from the medium in which they are suspended (Bony et al., 1997; Stratford, 1989). Moreover, flocculation is also a cooperative protection mechanism that shields cells from stressful environments (Vallejo et al., 2013). According to the lectin-like model, flocculent cells display proteins on the cell wall called flocculins (adhesins or zymolectins) that recognize and interact with the $\alpha$-mannose residues (receptors) of the neighboring cells. Calcium ions enable the lectins to achieve their active conformation (Miki et al., 1982). Most likely, besides specific interactions (lectin-sugar), other nonspecific interactions such as those triggered by cell wall charge or hydrophobicity reinforce and stabilize the flocculent-cell interaction (Soares, 2010).

From the complete sequence of the yeast genome, 33 genes are known to be associated with flocculation (Heine et al., 2009). There are five dominant FLO genes, including the subtelomeric genes FLO1, FLO5, FLO9, and FLO10 (Goossens and Willaert, 2010; Teunissen and

\footnotetext{
* Corresponding author at: Laboratório de Biologia Celular e Molecular, Núcleo de Pesquisas em Ciências Biológicas, ICEB II, Universidade Federal de Ouro Preto, Campus do Morro do Cruzeiro, CEP 35.400-000 Ouro Preto, Minas Gerais, Brazil. Fax: + 553135591680. E-mail address: rlbrand@nupeb.ufop.br (R. Lopes Brandão).

1 These two authors participated equally in this work.
}

Steensma, 1995; Verstrepen et al., 2003) and the nonsubtelomeric gene FLO11/MUC11, which encodes for another protein that is associated with flocculation and other cellular processes (Bester et al., 2012; Govender et al., 2008, 2011; Lo and Dranginis, 1998). Interestingly, it has also been demonstrated that an increase in the hydrophobicity of the yeast cellular surface is associated with the presence of the proteins encoded by the FLO1, FLO5, FLO9, and FLO11 genes (Govender et al., 2008; Van Holle et al., 2012; Van Mulders et al., 2009; Verstrepen and Klis, 2006).

All Flo proteins are glycosylphosphatidyl-inositol-linked glycoproteins that share a common three-domain structure, consisting of an amino-terminal lectin domain, a central domain of highly repeated sequences rich in serine and threonine residues, and a carboxy-terminal domain containing a glycosylphosphatidylinositol-anchoring sequence (Bony et al., 1997; Verstrepen and Klis, 2006). The N-terminal domain is proposed to harbor the binding site to carbohydrate receptors (Kobayashi et al., 1998). However, the Flo11-domain self-interacts and does not bind to mannose residues, which is in contrast to the other Flo proteins (Goossens and Willaert, 2012).

According to carbohydrate receptor recognition, two main flocculation phenotypes, namely Flo1 and NewFlo, have been described in Saccharomyces cerevisiae cells (Stratford and Assinder, 1991). The Flo1 phenotype is constitutively flocculent, exclusively mannose-sensitive, and generally associated with S. cerevisiae strains that express FLO1-, FLO5-, and FLO9-encoded flocculins (Bauer et al., 2010; Govender 
et al., 2008; Veelders et al., 2010). The NewFlo phenotype is typically associated with brewing strains that display stationary phase-specific flocculation, which is inhibited by maltose, mannose, glucose, and sucrose (but not by galactose) (Stratford and Assinder, 1991).

There is a particular flocculation phenotype governed by Lg-Flo1p and the flocculin homolog Flo1p, which was discovered in a Saccharomyces pastorianus strain (Kobayashi et al., 1998). The difference between Flo1p and Lg-Flo1p is the position of the pentapeptidic motif, which is placed in the N-terminal domain at position 226-230 in Flo1 and at 199-203 in Lg-Flo1p (Kobayashi et al., 1998). Moreover, it has been proposed that deletion of the internal repeats of the FLO1 gene affects the flocculation phenotype conversion from Flo1 to NewFlo (Liu et al., 2007). Furthermore, there is also another described phenotype, called mannose insensitive, which is independent of calcium ions and results in hydrophobic interactions and the involvement of the flocculin Flo11p (Bauer et al., 2010; Soares, 2010; Verstrepen et al., 2003).

In the particular case of the brewery industry, yeast cells have been classified into two groups based on their ability to form flocs that either rise to the surface of the liquid medium (top-fermenting) or sediment to the bottom of the fermentation tanks (bottom-fermenting) (Dengis and Rouxhet, 1997). Both ale (top-fermenting) and lager (bottomfermenting) strains belong to the NewFlo phenotype and flocculate at the end of the fermentation process (Vallejo et al., 2013). Besides this distinction, ale and lager yeast strains exhibit very different physiological traits, which result in beers with their own characteristic taste (Van Mulders et al., 2010). Curiously, Van Mulders et al. (2010) have detected a typical lager yeast flocculation gene, $L g$-FLO1, in three strongly flocculating ale strains.

Interestingly, different flocculation traits have been observed in yeast strains isolated from fermentation vats during the production of cachaça, the Brazilian spirit obtained from the distillation of fermented sugarcane juice. Due to the fact that the majority of the cachaça producers do not use centrifugation to separate yeast cells and fermented must (also called wine) before distillation in copper alembics, a fast flocculation at the end of each fermentation cycle is considered essential (Vicente et al., 2006).

In this work, we attempted to characterize the flocculation profiles of $S$. cerevisiae strains isolated from fermentation vats of different cachaça distilleries that presented bottom- or top-fermenting behavior. The main goal was to understand the flocculation behavior at biochemical and molecular level as additional criteria to choose these yeast cells to be used in the beverage industries (for instances, cachaça distilleries and breweries). We showed that the combined application of the available biochemical and molecular methodologies described in the literature is insufficient to understand the flocculation mechanisms in cachaça yeast strains and to establish patterns that enable the differentiation between Flo1/NewFlo phenotypes with bottom- or topfermenting behavior.

\section{Materials and methods}

\subsection{Yeast strains and culture conditions}

The thirteen native yeast strains used in this work were isolated from cachaça distilleries located in Minas Gerais and Bahia states (Brazil). The main criteria for yeast selection were based on S. cerevisiae biochemical and molecular characterizations, considering their resistance to stressful conditions during fermentation, ability to produce aromatic compounds, and capacity to flocculate, among others (Oliveira et al., 2008; Vicente et al., 2006).

Yeast cells were grown under laboratory conditions at $30{ }^{\circ} \mathrm{C}$ in YPD medium [1\% $(\mathrm{w} / \mathrm{v})$ yeast extract, $2 \%(\mathrm{w} / \mathrm{v})$ peptone, and $2 \%(\mathrm{w} / \mathrm{v})$ glucose]. Solid medium was supplemented with agar [2\% (w/v)]. All yeast strains were stored in $30 \%(\mathrm{v} / \mathrm{v})$ glycerol at $-80{ }^{\circ} \mathrm{C}$ for longterm storage. For short-term maintenance, cultures were kept in YPD agar at $4{ }^{\circ} \mathrm{C}$.
The commercial brewing strains S. pastorianus W34/70 (lager yeast) and S. cerevisiae WB-06 (ale yeast) (Fermentis, Germany) as well as strain S. cerevisiae BY4741 (isogenic to S288C) (EUROSCARF collection) were used in different tests as controls.

\subsection{Differentiation between ale and lager yeast strains by the ASBC criteria}

According to the American Society of Brewing Chemists (ASBC), three tests allow differentiation of brewery ale strains (e.g., S. cerevisiae) from lager strains (e.g., S. pastorianus): growth at $37{ }^{\circ} \mathrm{C}$, melibiose utilization, and melibiase secretion (X-alpha-gal test) (ASBC, 1992).

Briefly, to test the capacity of strains to grow at $37^{\circ} \mathrm{C}$, all strains were inoculated on plates containing YPD agar and grown at $25^{\circ} \mathrm{C}$ and $37{ }^{\circ} \mathrm{C}$, respectively, for 5 days. To verify the capacity to grow on melibiose, all strains were inoculated in tubes $(16 \mathrm{~mm} \times 100 \mathrm{~mm})$, with inverted Durham tubes, containing $7 \mathrm{~mL}$ of yeast nitrogen base (YNB) medium with $4 \%(\mathrm{w} / \mathrm{v})$ melibiose and $0.002 \%(\mathrm{w} / \mathrm{v})$ bromocresol green (autoclaved for $10 \mathrm{~min}$ at $121{ }^{\circ} \mathrm{C}$ and $15 \mathrm{psi}$ ). The tubes were incubated at $30{ }^{\circ} \mathrm{C}$ for 6-8 days. A color change from blue to yellow and the production of gas $\left(\mathrm{CO}_{2}\right)$ in the Durham tubes were used as an indication that the sugar had been fermented. Finally, to differentiate an $\alpha$-galactosidase (melibiase)-secreting yeast (lager) from a nonsecreting yeast (ale), the chromogenic substrate 5-bromo-4-chloro-3-indolyl- $\alpha$-galactoside $(\mathrm{X}-\alpha$-gal) was used. In plates containing $2 \%(\mathrm{w} / \mathrm{v})$ glycerol, $0.2 \%(\mathrm{w} / \mathrm{v})$ D-galactose, $1 \%(\mathrm{w} / \mathrm{v})$ yeast extract, $2 \%(\mathrm{w} / \mathrm{v})$ bacto-peptone, and $2 \%(\mathrm{w} / \mathrm{v})$ agar, $3 \%(\mathrm{w} / \mathrm{v})$ ethanol was added just after the sterilization. After solidification, $10 \mu \mathrm{L}$ of $\mathrm{X}$ - $\alpha$-gal solution ( $25 \mathrm{mg}$ dissolved in $1.25 \mathrm{~mL}$ of $\mathrm{N}, \mathrm{N}$-dimethylformamide) was added and the plates were incubated in the dark for at least $30 \mathrm{~min}$. Immediately, the yeast strains were spread on the plates and incubated at $25^{\circ} \mathrm{C}$ in the dark for 6 days. The indole released by the enzymatic cleavage afforded an insoluble blue-green dye that does not diffuse in agar. Hence, when grown on this medium, ale yeast colonies remain white, whereas lager yeast colonies turn blue-green.

\subsection{Flocculation assay}

Flocculation ability was evaluated by using the modified Helm's assay as described by D'Hautcourt and Smart (1999). Cultures in logarithmic or stationary phases of growth were grown on YPD medium at $30{ }^{\circ} \mathrm{C}$ with shaking at $200 \mathrm{rpm}$. At the appropriate times, the cultures were washed twice with $0.5 \mathrm{M}$ EDTA ( $\mathrm{pH} 7)$ to break the cell aggregates. The cells that were insensitive to EDTA were sonicated to ensure cell separation, according to the method described by Powell et al. (2003). The flocculation test was carried out starting with approximately $10^{8} \mathrm{UFC} / \mathrm{mL}\left(\mathrm{OD}_{600} \mathrm{~nm}\right.$ 0.35-0.4) and was performed in Eppendorf tubes using successive washes with $0.51 \mathrm{~g} / \mathrm{L} \mathrm{CaSO}_{4}$ solution and resuspended in a solution containing $0.51 \mathrm{~g} / \mathrm{L} \mathrm{CaSO}_{4}, 6.8 \mathrm{~g} / \mathrm{L}$ sodium acetate, $4.05 \mathrm{~g} / \mathrm{L}$ acetic acid, and $4 \%$ (v/v) ethanol ( $\mathrm{pH} 4.5$ ). Yeast cells in control tubes were resuspended in 0.5 M EDTA ( $\mathrm{pH} 7$ ). After a sedimentation period of 15 min, samples $(100 \mu \mathrm{L})$ were taken from just below the meniscus and dispersed in $\mathrm{H}_{2} \mathrm{O}(900 \mu \mathrm{L})$; then, the absorption at $600 \mathrm{~nm}$ was measured. Six replicates were performed for each sample, and the percentage of flocculation reported reflects the mean of three independent determinations. To investigate sugar inhibition of flocculation phenotypes, either $1 \mathrm{M}$ mannose or $1 \mathrm{M}$ glucose was added to both the washing and suspension solutions that were employed in the modified Helm's assay.

\subsection{Hydrophobicity of yeast cell surfaces}

The hydrophobicity of yeast cell surfaces was determined by measuring the distribution ratio of yeast cells in a biphasic system consisting of a buffered solution and xylene as the organic solvent, according to Rosenberg et al. (1980). The average modified hydrophobic index (MHI) for each sample was calculated as previously 
described by Govender et al. (2008). The strains were considered hydrophobic when the adsorption to xylene (organic phase) was greater than $35 \%$.

\subsection{Analysis of glucose and mannose residues on the cell surface}

Analysis of glucose and mannose residues on the cell surface were carried out by using the fluorescent lectins Pisum sativum agglutinateFITC conjugate (PSA-FITC, Sigma-Aldrich ${ }^{\circledR}$ ) and Concanavalin A-Alexa Fluor ${ }^{\circledR} 647$ (ConA-AF, Invitrogen $\left.{ }^{\circledR}\right)$, respectively (Heine et al., 2009). Before staining, the yeast cells were harvested after $48 \mathrm{~h}$ of growth on YNB medium, deflocculated with EDTA or sonication, washed twice with phosphate-buffered saline (PBS; pH 7.2) and finally resuspended in PBS buffer until $1 \times 10^{7} \mathrm{UFC} / \mathrm{mL}\left(\mathrm{OD}_{600 \mathrm{~nm}} \approx 0.3-0.4\right)$. All staining procedures were performed in the dark on ice using a $1 \mathrm{mg} \mathrm{mL}^{-1}$ dye stock solution. The diluted cell suspension $(10 \mu \mathrm{L})$ was suspended in $200 \mu \mathrm{L}$ of PBS and stained with $50 \mu \mathrm{L}$ of PSA-FITC (diluted $1 / 300$ from the stock solution) for $30 \mathrm{~min}$. Once the cells were washed with PBS, they were incubated with $50 \mu \mathrm{L}$ of ConA-Alexa Fluor ${ }^{\circledR} 647$ (diluted 1/ 10,000 from the stock solution) for $30 \mathrm{~min}$. Next, the samples were washed twice with PBS and immediately analyzed by flow cytometry (FACSCalibur ${ }^{\circledR}$, Becton Dickinson, USA). A total of 20,000 cells were analyzed in each sample. Data were evaluated using the program FlowJo (version 7.6.1, Tree Star Inc., Ashland, OR).

\subsection{Detection and quantification of FLO genes}

The intragenic repetitive domain polymorphisms located within the FLO1, FLO5, and FLO11 genes of the cachaça yeast strains were evaluated using the following primer sets designed by Verstrepen et al. (2005): FLO1-reps-F (5'-CTAAGTCAATCTAACTGT ACTGTCCCTGA-3'), FLO1reps-R (5'-GATAGAGCTGGTGATTTGTCCTGAA-3'), FLO5-reps-F (5'AAGGGTACGTTTACTCTTTTGACGATGACC-3'), FLO5-reps-R (5'-ACTGAA GAA GAAATTACTGAGGAGGAAATC-3'), FL011-reps-F (5'-TAGTGCCG CTCAATATGCAAGCT CCTGGCA-3'), and FLO11-reps-R (5'-TGTTTGAC TGCCAGGGTATTTGGATGATGA-3').

Genomic DNA preparations and agarose gel electrophoresis were performed according to the standard protocols described by Ausubel et al. (1995). Polymerase chain reaction (PCR) amplifications were carried out in a $25-\mu \mathrm{L}$ reaction mixture containing approximately $300 \mathrm{ng}$ of genomic DNA, $1 \times$ PCR buffer, $0.25 \mathrm{mM}$ each of deoxynucleoside triphosphate (Promega, Madison, WI), 20 pmol of each primer (forward and reverse), $1.5 \mathrm{mM} \mathrm{MgCl}_{2}$, and $0.5 \mathrm{U}$ of Taq DNA polymerase (Invitrogen, Carlsbad, CA). The PCR program consisted of an initial denaturation at $95{ }^{\circ} \mathrm{C}$ for $3 \mathrm{~min}$, followed by 30 cycles of $94{ }^{\circ} \mathrm{C}$ for $1 \mathrm{~min}, 60{ }^{\circ} \mathrm{C}$ for $1 \mathrm{~min}$, and $70{ }^{\circ} \mathrm{C}$ for $1 \mathrm{~min}$. A final extension step at $70{ }^{\circ} \mathrm{C}$ for 5 min was performed.

Samples of yeast cells corresponding to the exponential $(6 \mathrm{~h})$ and stationary $(24 \mathrm{~h})$ growth phases were used to analyze the expression levels of FLO1, Lg-FLO1, FLO5, and FLO11 genes. RNA extraction was performed as described by Souza et al. (2012). Total RNA concentration and purity were determined by spectrophotometric analysis at $260 \mathrm{~nm}$ and $280 \mathrm{~nm}$ on a NanoVue spectrophotometer (GE Healthcare, UK). cDNA was synthesized from total RNA using a high capacity cDNA Reverse Transcription kit® (Life Technologies, Carlsbad, CA, USA), according to the manufacturer's instructions. Real-time PCRs (q-PCRs) were performed on an ABI7300 instrument using SYBR Green PCR Master Mix (Applied Biosystems, Foster City, CA). FLO gene expression was normalized to that of the ACT1 gene (Fw 5'-CGTCTGGATTGGTGGTTCT-3' and Rv 5'-GTGGTGAACGATAGATGGAC-3'). Primer sequences (Fw 5'TGCCTCATCGCTATATGTTTTTGG-3' and Rv 5' - TTCCTCTGGCCTGCTGGT AA-3' for FLO1; Fw 5'-CACCTACCGACATAAAGGGGT-3' and Rv 5'ACAGGAAGCCTAGCCAAGAC-3' for $L g$-FLO1; Fw 5'-GCTATTGTTTCCAC GGCCAC-3' and Rv 5'-GGTAGAAATAGGGCACCACG-3' for FLO5; and Fw 5'-TGTTCTGCTGCTACAAACGC-3' and Rv 5'-CCGAAGGTGCAGTGTT TTCG-3' for FLO11) were obtained using the Primers-BLAST program
(NCBI database) and checked with OligoAnalyzer 3.1 (Integrated DNA Technologies,Coralville, IA, USA). The amplification reactions were performed as follows: $2 \mathrm{~min}$ at $50{ }^{\circ} \mathrm{C}, 10 \mathrm{~min}$ at $95{ }^{\circ} \mathrm{C}$, and 40 cycles of $95{ }^{\circ} \mathrm{C}$ for $15 \mathrm{~s}$ and $60{ }^{\circ} \mathrm{C}$ for $1 \mathrm{~min}$. To confirm primer specificity, the dissociation curves of all amplification products were analyzed using the ABI7300 instrument. Variation in gene expression was quantified using the comparative $\mathrm{Ct}$ method, $2^{-(\Delta \mathrm{CtFL}-\triangle \mathrm{CtACT1})}$, which is based on the comparison of the target gene expression (normalized to the endogenous control) between experimental and control samples (Livak and Schmittgen, 2001). All primers used were purchased from IDT Síntese Biotecnologia LTDA-EPP, Minas Gerais, Brazil.

\subsection{Statistical analysis}

The experiments were performed at least three times with consistent results. Standard deviations are indicated in each figure or table. Statistical analyses were accomplished by using the Tukey test. Differences were considered statistically significant when the $P$ value was less than 0.05 .

\section{Results}

\subsection{Application of the ASBC criteria to cachaça yeast strains}

By collecting and isolating yeast cells from cachaça distilleries, we observed that the cells exhibited flocculation behaviors similar to those presented by brewery yeast cells described as bottom- (lager) or topfermenting (ale) strains (Table 1). According to the ASBC criteria, it is possible to classify lager (e.g., S. pastorianus) and ale (e.g., S. cerevisiae) strains based on their ability to grow at $37{ }^{\circ} \mathrm{C}$ as well as ferment melibiose and secrete melibiase. Therefore, thirteen $S$. cerevisiae strains isolated from spontaneous fermentation in different cachaça distilleries were initially characterized based on these criteria. Independent of this apparent behavior as bottom- or top-fermenting strains, all cachaça yeast strains grew at $37^{\circ} \mathrm{C}$, which is typical of ale strains. However, three of them (strains C29, C45, and C67) were able to ferment melibiose and secrete melibiase, similar to lager brewing strains (Table 1). These results initially suggested that the ale and lager classification according to the ASBC is not enough to explain the flocculation behavior of cachaça yeast strains.

\subsection{Flocculation profile and cell wall hydrophobicity of cachaça yeast} strains

Characteristics associated with flocculation such as the percentage of flocculation, EDTA sensitivity, cell wall hydrophobicity, and flocculation

Table 1

Classification of ale and lager yeasts based on the metabolic characteristics proposed by the ASBC.

\begin{tabular}{lllll}
\hline Strain & $\begin{array}{l}\text { Fermentation } \\
\text { behavior }\end{array}$ & $\begin{array}{l}\text { Growth } \\
\text { at } 37{ }^{\circ} \mathrm{C}\end{array}$ & $\begin{array}{l}\text { Melibiose } \\
\text { fermentation }\end{array}$ & $\begin{array}{l}\text { Melibiase } \\
\text { secretion }\end{array}$ \\
\hline C00 & Top-fermenting & + & - & - \\
C01 & Bottom-fermenting & + & - & - \\
C10 & Top-fermenting & + & - & - \\
C13 & Top-fermenting & + & - & - \\
C20 & Top-fermenting & + & - & - \\
C21 & Top-fermenting & + & - & - \\
C29 & Top-fermenting & + & + & + \\
C32 & Bottom-fermenting & + & - & - \\
C45 & Top-fermenting & + & + & + \\
C67 & Top-fermenting & + & + & + \\
C78 & Top-fermenting & + & - & - \\
C80 & Top-fermenting & + & - & - \\
C92 & Bottom-fermenting & + & - & + \\
W34/70 & Bottom-fermenting & - & + & - \\
WB-06 & Top-fermenting & + & - & - \\
& & & & - \\
\end{tabular}


Table 2

Flocculation profile and cell surface hydrophobicity in thirteen cachaça strains as well as commercial lager (W34/70) and ale (WB-06) brewing strains.

\begin{tabular}{|c|c|c|c|c|c|c|}
\hline \multirow[t]{2}{*}{ Strain } & \multicolumn{2}{|c|}{ Flocculation (\%) } & \multirow[t]{2}{*}{$\begin{array}{l}\text { EDTA } \\
\text { sensitivity }\end{array}$} & \multirow[t]{2}{*}{$\begin{array}{l}\text { Hydrophobicity } \\
\text { (MHI) }\end{array}$} & \multicolumn{2}{|c|}{$\begin{array}{l}\text { Flocculation in the } \\
\text { presence of sugars } \\
(\%)\end{array}$} \\
\hline & $6 \mathrm{~h}$ & $72 \mathrm{~h}$ & & & $\begin{array}{l}\text { Glucose } \\
(1 \mathrm{M})\end{array}$ & $\begin{array}{l}\text { Mannose } \\
(1 \mathrm{M})\end{array}$ \\
\hline $\mathrm{COO}$ & $74 \pm 7^{a}$ & $49 \pm 9$ & - & $0.89 \pm 0.00$ & $0^{*}$ & $6 \pm 7^{*}$ \\
\hline C01 & $24 \pm 5$ & $30 \pm 6$ & + & 0 & $3 \pm 2^{*}$ & $7 \pm 3^{*}$ \\
\hline C10 & $71 \pm 5^{a}$ & $64 \pm 3^{c}$ & + & $0.58 \pm 0.06$ & $26 \pm 4^{*}$ & $23 \pm 2^{*}$ \\
\hline C13 & $31 \pm 6$ & $28 \pm 7$ & + & $0.45 \pm 0.02$ & $22 \pm 3$ & $19 \pm 6$ \\
\hline $\mathrm{C} 20$ & $36 \pm 11$ & $43 \pm 3$ & + & 0 & $2 \pm 1^{* *}$ & $23 \pm 15^{*}$ \\
\hline C21 & $77 \pm 6^{a}$ & $67 \pm 10^{c}$ & - & $0.7 \pm 0.05$ & $38 \pm 7^{*}$ & $33 \pm 6^{*}$ \\
\hline C29 & $72 \pm 7$ & $81 \pm 8^{b}$ & - & $0.43 \pm 0.06$ & $37 \pm 8^{*}$ & $52 \pm 9^{*}$ \\
\hline C32 & $69 \pm 7^{a}$ & $40 \pm 6$ & + & 0 & $14 \pm 2^{*}$ & $1 \pm 2^{* *}$ \\
\hline C45 & $76 \pm 7$ & $84 \pm 5^{\mathrm{ab}}$ & - & $0.83 \pm 0.04$ & $42 \pm 9^{* *}$ & $56 \pm 6^{*}$ \\
\hline C67 & $32 \pm 13$ & $40 \pm 5$ & + & $0.12 \pm 0.06$ & $23 \pm 4^{*}$ & $18 \pm 2^{*}$ \\
\hline C78 & $45 \pm 5$ & $40 \pm 8$ & + & $0.57 \pm 0.00$ & $2 \pm 4^{*}$ & $4 \pm 5^{*}$ \\
\hline $\mathrm{C} 80$ & $40 \pm 8$ & $36 \pm 6$ & + & $0.66 \pm 0.02$ & $5 \pm 4^{*}$ & $0^{*}$ \\
\hline C92 & $94 \pm 2$ & $96 \pm 2^{\mathrm{a}}$ & + & $0.74 \pm 0.01$ & $89 \pm 3$ & $56 \pm 4^{*}$ \\
\hline $\begin{array}{c}\text { W34/ } \\
70\end{array}$ & $28 \pm 10$ & $35 \pm 5$ & + & 0 & $0^{*}$ & $0^{*}$ \\
\hline WB-06 & $28 \pm 3$ & $44 \pm 4^{a}$ & + & 0 & $16 \pm 10^{*}$ & $16 \pm 9^{*}$ \\
\hline
\end{tabular}

Different letters indicate statistically significant differences among flocculation percentages of cachaça strains recorded in the stationary growth phase compared with the reference brewing strains W34/70 and WB-06.

*/**Statistically significant differences among flocculation percentages in the presence of glucose or mannose compared with the flocculation percentage without the presence of sugar during the stationary growth phase for the same strain.

a Statistically significant differences between flocculation percentages of exponential and stationary growth phases for the same strain.

inhibition by sugars (related to phenotypic profiles) were evaluated in the cachaça yeast strains and two industrial brewing strains (lager W34/70 and ale WB-06) (Table 2). According to the modified Helm's assay, nine cachaça strains (C01, C13, C20, C29, C45, C67, C78, C80, and $\mathrm{C92}$ ) presented a constitutive flocculation profile, without differences between the exponential ( $6 \mathrm{~h})$ and stationary ( $72 \mathrm{~h}$ ) growth phases. Therefore, they exhibited the same flocculation pattern when compared with a typical brewery lager strain such as $S$. pastorianus W34/70. On the other hand, none of the cachaça yeast strains showed a typical ale behavior characterized by a flocculation rate in the stationary growth phase higher than logarithmic growth phase, as observed for S. cerevisiae WB-06. Interestingly, four cachaça strains (C00, $\mathrm{C} 10, \mathrm{C} 21$, and $\mathrm{C} 32$ ) presented a higher flocculation rate in the exponential growth phase compared to the stationary growth phase.

In addition, five cachaça strains (C10, C21, C29, C45, and C92) presented flocculation percentages higher than those of the brewing reference strains during the stationary growth phase. From these, strains C21, C29, and C45, as well as C00, were insensitive to EDTA. Moreover, higher values of cell surface hydrophobicity (indices $>0.6$ ) were detected in strains C00, C21, C45, C80, and C92. Together, these results suggest that there is no direct correspondence between flocculation intensity, sensitivity to calcium, and level of hydrophobicity for cachaça yeast strains.

The presence of glucose and mannose sugars in the medium (flocculation inhibition profile) allowed three flocculation phenotypes to be differentiated. Almost all of the cachaça yeast strains, as well as the brewing reference strains, presented the NewFlo phenotype (glucose/ mannose-sensitive flocculation); the only exceptions were strain C92, which showed the Flo1 phenotype (mannose-sensitive flocculation), and strain $\mathrm{C} 13$, which showed the mannose-insensitive phenotype, although its flocculation profile was sensitive to EDTA.

Altogether, these data provide us an overall impression that in this particular industrial sector, i.e., cachaça distilleries, it is apparently difficult to find a normal pattern of flocculation (Flo1 or NewFlo) by which the yeast strains can be classified, according to previously described criteria normally found in the literature.

\subsection{Presence of glucose and mannose residues on the cell surface}

Fluorescent probes and flow cytometry were used to determine the mannose/glucose residue ratio present on the yeast cell wall. According to the flocculation phenotypes described, the flocculent yeast cells, at least those presenting the Flo1 phenotype, possess greater amounts of mannose residues on the cell surface and consequently a higher mannose/ glucose ratio than nonflocculent strains (Stratford and Assinder, 1991). Based on this concept, the lectin concanavalin A was proposed as the main marker of flocculent yeast, due to its capacity to bind mannose residues stronger than the lectin PSA; while PSA has been preferentially described as a glucose-binding lectin (Heine et al., 2009).

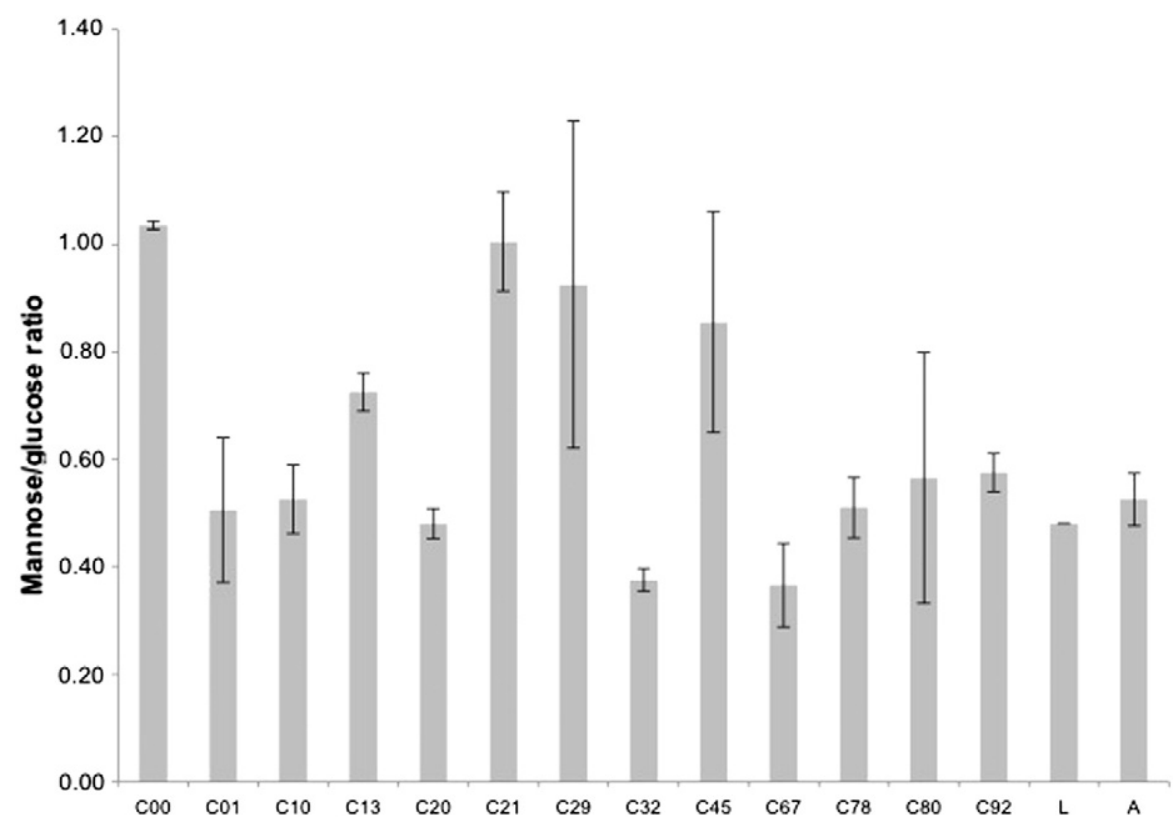

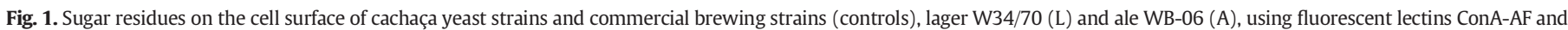
PSA-FITC. The mean \pm standard deviations (SD) of the mannose/glucose ratios from three experiments are shown as bars. 


\section{FLO1}
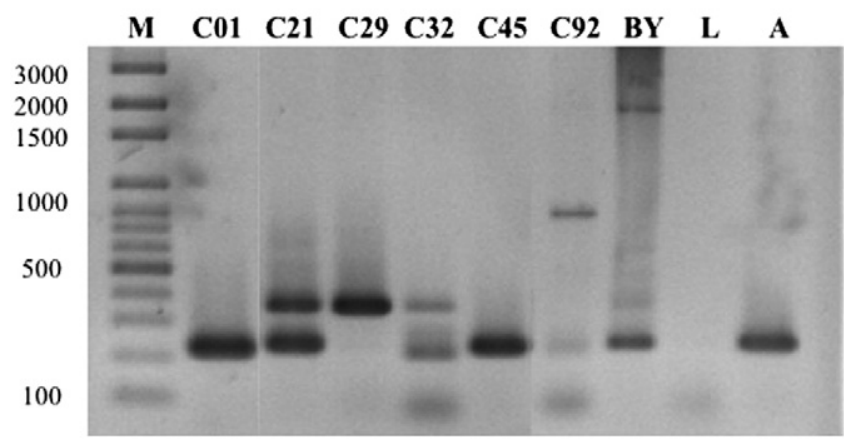

\section{FLO5}
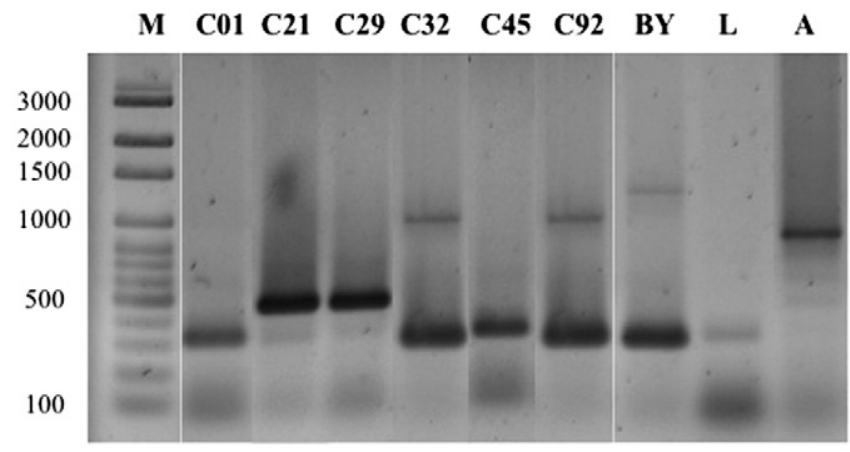

\section{FLO11}

$\begin{array}{llllllllll}M & C 01 & \text { C21 } & \text { C29 } & \text { C32 } & \text { C45 } & \text { C92 } & \text { BY } & \text { L } & \text { A }\end{array}$

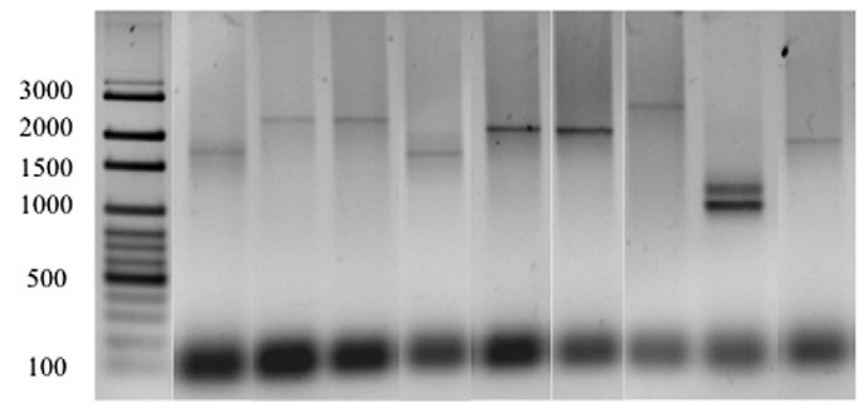

Fig. 2. PCR detection of FLO intragenic repetitive domain polymorphisms using primers designed by Verstrepen et al. (2005) in six cachaça yeast strains and the lager and ale brewing strains W34/70 (L) and WB-06 (A). The laboratory strain BY4741 (BY) was used as a control in which the molecular weights of FLO1, FLO5, and FLO11 genes corresponded to 2529, 1288, and 2260 bp, respectively. M: 100 bp DNA Ladder (Axygen Scientific, Inc., Union City, CA, United States).

Nevertheless, our results showed that there was no correspondence between the presence of sugar residues and flocculation phenotypes in cachaça yeast strains. As shown in Fig. 1, none of the strains presented a greater number of mannose residues than glucose residues on the cell surface. Similar proportions of both types of sugars were detected in EDTA-insensitive strains C00, C21, C29, and C45, which showed the typical NewFlo phenotype during sugar inhibition (Table 2). Moreover, strain C92, with the typical Flo1 phenotype, exhibited two times more glucose residues than mannose residues on the cell wall, similar to some strains with the NewFlo phenotype (C01, C10, C20, C78, and C80), including reference brewing yeast strains. Finally, the greatest levels of glucose residues on the cell surface were detected in strains C32 and C67. Although both strains showed the NewFlo phenotype, strain C32 showed a bottom-fermenting behavior and differential flocculation during the two growth phases, unlike strain C67. Thus, the use of fluorescent lectins to differentiate flocculent phenotypes among cachaça yeast strains was not feasible.

\subsection{Analysis of FLO genes}

Due to all these previous results found in cachaça yeast strains, we focused on the analysis of FLO genes (molecular approaches) for three flocculent top-fermenting strains (C21, C29, and C45) and three bottom-fermenting strains (C01, C32, and C92). Initially, the FLO1, FLO5, and FLO11 genes were amplified by PCR using primers designed by Verstrepen et al. (2005). These primers amplify intragenic repetitive sequences within the central domain of $F L O$ genes, allowing gene differentiation according to the number of these intragenic repetitive sequences. Our results demonstrated that the three FLO genes evaluated were detected in all cachaça yeast strains, displaying repetitive regions with smaller lengths when compared to the corresponding amplicons obtained from the laboratory strain BY4741 (Fig. 2). Based on the molecular weights, 2-6, 3-6, and 11-14 repetitive sequences for FLO1, FLO5, and FLO11, respectively, were found in the various cachaça strains. The largest amplicons among the cachaça and brewing strains were found in strain C92 for the three FLO genes as well as in strains C32 for FLO5 and C21, C29, and C45 for FLO11.

Furthermore, transcripts from the six cachaça yeast strains were obtained in order to quantify the relative expression of the FLO genes compared to the ale and lager brewing strains in the two different growth phases. Total RNAs from the exponential ( $6 \mathrm{~h}$ ) and stationary (24 h) growth phases were obtained, and q-PCR was performed. Considerable FLO1 expression levels were observed in strains C01 and C92 during the exponential growth phase, with values approximately 4-5fold greater than that of brewing strain WB-06 at the same growth phase (Fig. 3 - Panel A). As expected, FLO1 expression in the ale brewing strain was 6 -fold greater during the stationary growth phase. The homologous FLO1 gene, $L g$-FLO1, was expressed only in the lager strain W34/70, with transcription levels approximately 40-fold greater during the stationary phase (Fig. 3 - Panel B). Remarkable values of FLO5 relative expression were observed in strains C01, C32, and especially C92 during the exponential phase, corresponding to 9-, 10-, and 50 -fold greater than that of ale strain WB-06 (Fig. 3 - Panel C). Meanwhile, strain C29 expressed FLO5 values almost 2-fold greater than strain WB-06 during the stationary phase (Fig. 3 - Panel C). Moreover, FLO11 expression was remarkable in strains C21 and C29 during the stationary phase, whereas it was not expressed in the brewing strains (Fig. 3 - Panel D).

In general, these results showed that the FLO1 and FLO5 genes, which are involved in the Flo1 phenotype, were mainly expressed in the bottom-fermenting cachaça strains at the exponential growth phase. On the other hand, expression of the FLO11 gene, which is responsible for the mannose-insensitive phenotype, was relevant in the topfermenting cachaça strains C21 and C29 during the stationary growth phase, although it was not expressed in strain C45. Again, it was not possible to establish a clear correspondence among FLO gene expression, differential flocculation in either growth phase, and flocculent phenotypes observed in the cachaça yeast strains evaluated.

\section{Discussion}

Yeast flocculation is an important mechanism used by the fermented beverage industry because flocculation helps to conveniently separate cells (biomass) from the fermented broth by a low-cost sedimentation process. Particularly, in cachaça distilleries, the use of flocculent strains as starters for cachaça production aids in cell recovery at the end of daily fermentation cycles. Although yeast flocculation has been explored for a long time, the mechanism underlying this phenomenon is still not fully understood due to the intrinsic complexity of FLO genes and hydrophobic interactions as well as extrinsic factors (Soares, 2010; Vallejo et al., 2013). In the present study, we applied previously reported methodologies to thirteen $S$. cerevisiae strains isolated from cachaça distilleries in an attempt to understand and explain their flocculation behaviors. 

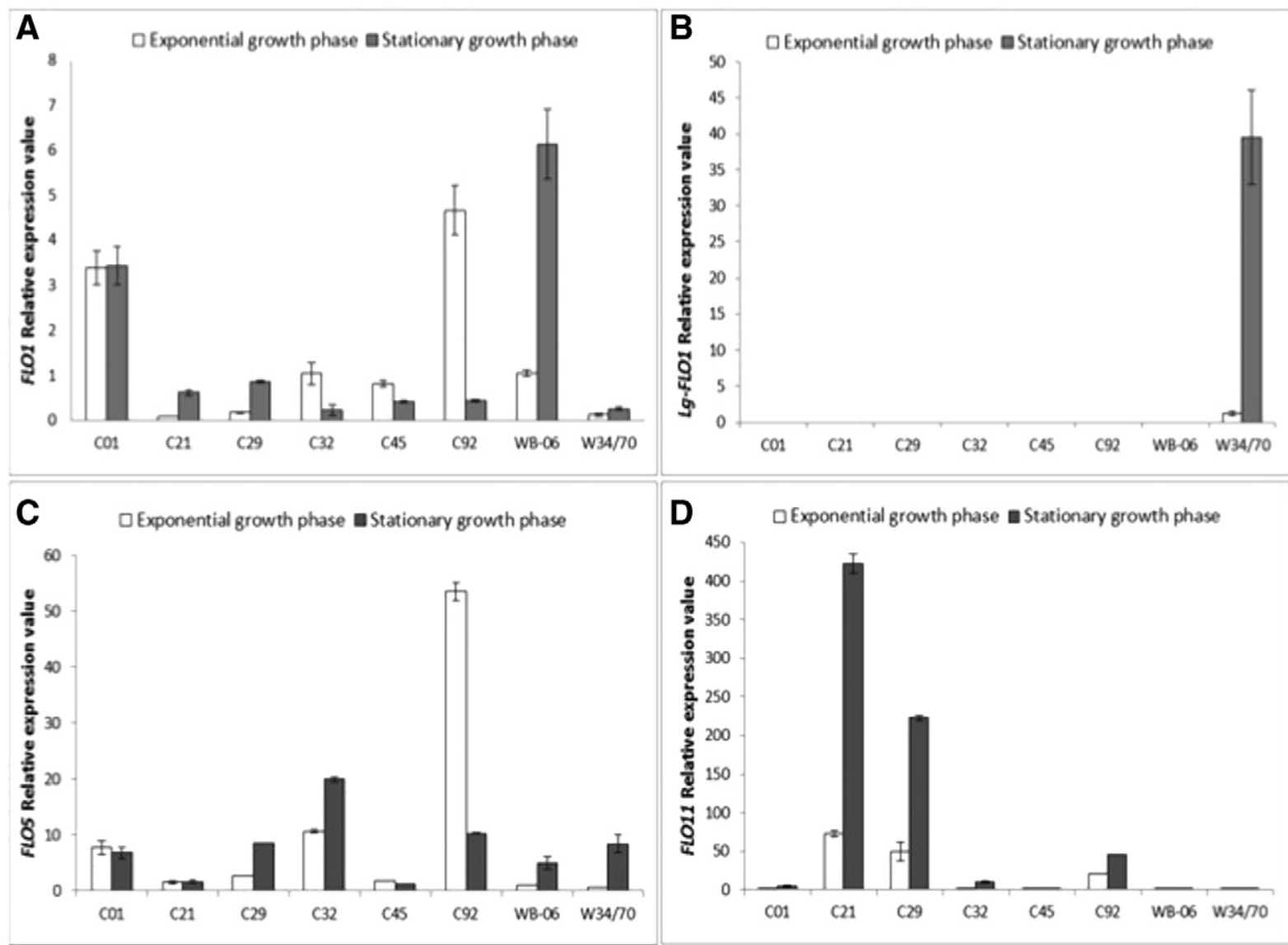

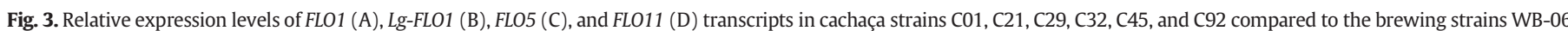

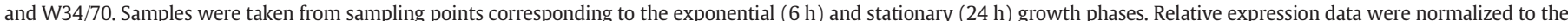
relative expression value of the housekeeping gene $A C T 1$. Values represent the means \pm standard deviations (SD) of experiments performed in triplicate.

Initially, it was observed that during cachaça fermentation, three of these thirteen yeast strains presented a bottom-fermenting behavior, while ten strains showed a top-fermenting profile. However, our results demonstrated that all top-fermenting cachaça strains exhibited the NewFlo phenotype, with the exception of strain C13, which demonstrated unaffected flocculation by mannose, despite being calcium-dependent. According to our data, calcium dependency, cell wall hydrophobicity, and sugar sensitivity in the flocculation profiles of cachaça yeast strains did not have a direct correspondence to flocculation strength, even when most of the flocculent strains exhibited high õhydrophobicity indices, as reported previously (Govender et al., 2008; Van Holle et al., 2012; Van Mulders et al., 2009).

Among the three bottom-fermenting cachaça strains, only strain C92 showed the typical Flo1 phenotype (mannose-sensitive flocculation) characterized for higher mannose residues on cell surface. Nevertheless, a mannose and glucose proportional content was detected on strain C92 through the use of fluorescent lectins. Unexpectedly, Heine et al. (2009) reported that flocculent yeast strains tended to display a greater number of glucose than mannose residues on the cell surface under defined conditions. According to our results, not necessarily the most flocculent cachaça strains were those that showed a lower mannose/glucose ratio.

With the aim to understand the flocculation patterns through a molecular approach, the expression levels of the main FLO genes (FLO1, Lg-FLO1, FLO5, and FLO11) were evaluated in six cachaça strains that exhibited top- or bottom-fermenting behavior and were compared with the lager (W34/70) and ale (WB-06) brewing strains. Previously, variable-size amplicons, based on the repetitive intragenic regions within the $F L O$ gene central domains (unit A), were detected in cachaça yeast strains. According to Verstrepen et al. (2005), the expansion of tandem sequence repeats within unit A results in a stronger cell-cell adhesion, while modifications in other units within the central domain (unit B, C, or D) increase the hydrophobicity of Flo1p due to a more stable protein conformation (Li et al., 2013a; Li et al., 2013b). A typical amplicons for FLO genes has been detected in the most flocculent strain C92, with a similar molecular weight as found in flocculent wine strains (Govender et al., 2010).

Relative expression of FLO genes was variable depending on the cachaça strain. In a general way, FLO1 and FLO5 were mainly expressed in the bottom-fermenting strains (C01, C32, and C92) at the exponential growth phase, while FLO11 was considerably expressed in topfermenting cachaça strains (C21 and C29) at the stationary growth phase with the exception of C45. Beyond asexual flocculation, the flocculin Flo11p has been shown to be involved in a wide range of adhesion phenotypes, such as invasive growth, pseudohyphal formation, biofilm formation, and adhesion to biotic and abiotic surfaces (Govender et al., 2008, 2011). In contrast to other flocculins, the Nterminal domain of Flo11p does not bind to mannose residues, but it shows the ability to self-interact, explaining the cell-cell interaction capacity of cells expressing FLO11 and the EDTA insensitivity (Goossens and Willaert, 2012).

None of the evaluated cachaça yeast strains expressed the typical lager flocculation gene Lg-FLO1, which is present in strain W34/70. Surprisingly, the complete Lg-FLO1 allele was detected in the genomes of three strongly flocculent ale strains isolated from breweries, suggesting that considerable genetic variability occurs in the subtelomeric chromosomal regions, where flocculation genes are located. Analyses performed on FLO genes, including the $L g$-FLO1 gene, revealed recombination breakpoints that afforded chimeric flocculins 
(Christiaens et al., 2012). In addition to recombination events across the central domain of these genes, a second type of recombination event occurs across small microhomologous regions in the $\mathrm{N}$ - or C-terminal domain that could subtly alter the strength and preference of the binding substrate, especially in the Flo1-like N-terminal domains (Christiaens et al., 2012). Thus, the almost null expression of FLO11 in strain C45 could be due to modifications in the $\mathrm{N}$-terminal domain that prevent binding of the primers used in the q-PCR assays.

Several industrial yeast strains, such as wine and lager yeasts, have resulted from hybridization events that took place in the Saccharomyces sensu stricto genus with adaptive advantages over the parental strains (Libkind et al., 2011; Querol and Bond, 2009). Recently, it has been demonstrated that different types of strains seem to coexist in cachaça fermentation with the presence of intraspecific hybrid ("mestizo") strains exhibiting both parental alleles found in wine or traditional fermentation from different geographical regions (Badotti et al., 2013). The fact that three cachaça S. cerevisiae strains (C29, C45, and C67) were able to grow at $37^{\circ} \mathrm{C}$, ferment melibiose, and secret melibiase suggests that they could likely be hybrid strains that are present in cachaça production environments. Therefore, we cannot discard the fact that the cachaça yeast strains used in this work can also be "mestizo" strains that present alleles coming from one or more strains and/or species, thus being constituted of new and interesting mixed phenotypes associated with bottom- or top- fermenting behavior. Allelic analyses could explain these mixed phenotypes and associate them with the fermentation behaviors.

It has already been observed that flocculation complexity lies not only in the phenotypic and genetic (FLO genes) variability but also in its own polygenic and multifactorial nature involving the participation of different genes. Indeed, the use of high-throughput approaches for quantitative trait locus mapping has allowed new yeast genes that contribute to the cell aggregation phenotype, such as AMN1 and RGA1 involved in cell separation and budding patterns, respectively, to be found (Li et al., 2013a; Li et al., 2013b; Wilkening et al., 2014).

In conclusion, our results demonstrate that the flocculation profiles of the yeast strains isolated from cachaça distilleries are associated with a high phenotypic variation. In general, although the expression levels of FLO genes contributed to explain the fermentation behavior in some of the most flocculent cachaça yeast strains, the application of conventional methodologies was not sufficient to predict flocculation behavior patterns.

\section{Conflicts of interest}

Authors wish to confirm that there are no known conflicts of interest associated with this publication and there has been no significant financial support for this work that could have influenced its outcome.

\section{Acknowledgments}

This work was supported by grants from Conselho Nacional de Desenvolvimento Científico e Tecnológico (CNPq) - Process 550584/ 2011-0 (fellowship to LFMC) and Process 304815/2012-3 (research grant to RLB); Fundação de Amparo à Pesquisa do Estado de Minas Gerais (FAPEMIG) - Process APQ-00263-10 (fellowship to FA and research grant); and Fundação de Capacitação de Pessoal de Nível Superior (CAPES/Brazil) - Process PNPD 2755/2011 (fellowship to LEFRC and research grant).

\section{References}

ASBC, 1992. Methods of Analysis, American Society of Brewing Chemists, 8th ed. St. Paul, Minnesota.

Ausubel, F.M., Brent, R., Kingston, R.E., Moore, D.D., Seidman, J.G., Struhl, K., 1995. Current Protocols in Molecular Biology, 2nd ed. John Wiley \& Sons, New York.
Badotti, F., Vilaça, S.T., Arias, A., Rosa, C.A., Barrio, E., 2013. Two interbreeding populations of Saccharomyces cerevisiae strains coexist in cachaça fermentations from Brazil. FEMS Yeast Res. http://dx.doi.org/10.1111/1567-1364.12108.

Bauer, F.F., Govender, P., Bester, M.C., 2010. Yeast flocculation and its biotechnological relevance. Appl. Microbiol. Biotechnol. 88, 31-39.

Bester, M.C., Jacobson, D., Bauer, F.F., 2012. Many Saccharomyces cerevisiae cell wall protein encoding genes are coregulated by Mss11, but cellular adhesion phenotypes appear only Flo protein dependent. Genetics 2, 131-141.

Bony, M., Thines-Sempoux, D., Barre, P., Blondin, B., 1997. Localization and cell surface anchoring of the Saccharomyces cerevisiae flocculation protein Flo1p. J. Bacteriol. 179, 4929-4936.

Christiaens, J.F., Van Mulders, S.E., Duitama, J., Brown, C.A., Ghequire, M.G., Meester, L.D., Michiels, J., Wenseleers, T., Voordeckers, K., Verstrepen, K.J., 2012. Functional divergence of gene duplicates through ectopic recombination. EMBO Rep. 13, 1145-1151.

D'Hautcourt, O., Smart, K.A., 1999. Measurement of brewing yeast flocculation. J. Am. Soc. Brew. Chem. 57, 123-128.

Dengis, P.B., Rouxhet, P.G., 1997. Surface properties of top- and bottom- fermenting yeast. Yeast 13, 931-943.

Goossens, K., Willaert, R., 2010. Flocculation protein structure and cell-cell adhesion mechanism in Saccharomyces cerevisiae. Biotechnol. Lett. 32, 1571-1585.

Goossens, K., Willaert, R., 2012. The N-terminal domain of the Flo11 protein from Saccharomyces cerevisiae is an adhesion without mannose-binding activity. FEMS Yeast Res. 12, 78-87.

Govender, P., Domingo, J.L., Bester, M.C., Pretorius, I.S., Bauer, F.F., 2008. Controlled expression of the dominant flocculation genes FLO1, FLO5, and FLO11 in Saccharomyces cerevisiae. Appl. Environ. Microbiol. 74, 6041-6052.

Govender, P., Bester, M., Bauer, F.F., 2010. FLO gene-dependent phenotypes in industrial wine yeast strains. Appl. Microbiol. Biotechnol. 86, 931-945.

Govender, P., Kroppenstedt, S., Bauer, F.F., 2011. Novel wine-mediated FLO11 flocculation phenotype of commercial Saccharomyces cerevisiae wine yeast strains with modified FLO gene expression. FEMS Microbiol. Lett. 317, 117-126.

Heine, F., Stahl, F., Sträuber, H., Wiacek, C., Benndorf, D., Repenning, C., Schmidt, F., Scheper, T., Von Bergen, M., Harms, H., Müller, S., 2009. Prediction of flocculation ability of brewing yeast inoculates by flow cytometry, proteome analysis, and mRNA profiling. Cytometry A 75, 140-147.

Kobayashi, O., Hayashi, N., Kuroki, R., Sone, H., 1998. Region of Flo1 proteins responsible for sugar recognition. J. Bacteriol. 180, 6503-6510.

Li, E.E., Yue, F., Chang, Q.I., Guo, X., He, X., Zhang, B., 2013a. Deletion of intragenic tandem repeats in unit C of FLO1 of Saccharomyces cerevisiae increases the conformational stability of flocculins under acidic and alkaline conditions. PLoS One 8, 53428-53438.

Li, J., Wang, L., Wu, X., Fang, O., Wang, L., Lu, C., Yang, S., Hu, X., Luo, Z., 2013b. Polygenic molecular architecture underlying non-sexual cell aggregation in budding yeast. DNA Res. 20, 55-66.

Libkind, D., Hittinger, C.T., Valério, E., Gonçalves, C., Dover, J., Johnston, M., Gonçalves, P., Sampaio, J.P., 2011. Microbe domestication and the identification of the wild genetic stock of lager-brewing yeast. Proc. Natl. Acad. Sci. U. S. A. 108, 14539-14544.

Liu, N., Wang, D.L., Wang, Z.Y., He, X.P., Zhang, B.R., 2007. Genetic basis of flocculation phenotype conversion in Saccharomyces cerevisiae. FEMS Yeast Res. 7, 1362-1370.

Livak, K.J., Schmittgen, T.D., 2001. Analysis of relative gene expression data using real-time quantitative PCR and the 2(-Delta-Delta C(T)) method. Methods 25, 402-408.

Lo, W.S., Dranginis, A.M., 1998. The cell surface flocculation Flo11 is required for pseudohyphae formation and invasion by Saccharomyces cerevisiae. Mol. Biol. Cell 9, 161-171.

Miki, B.L.A., Poon, N.H., James, A.P., Seligry, V.L., 1982. Possible mechanism for flocculation interactions governed by gene FLO1 in Saccharomyces cerevisiae. J. Bacteriol. 150, 878-889.

Oliveira, V.A., Vicente, M.A., Fietto, L.G., Castro, I.M., Coutrim, M.X., Schüller, D., Alves, H., Casal, M., Santos, J.O., Araújo, L.D., Silva, P.H.A., Brandão, R.L., 2008. Biochemical and molecular characterization of Saccharomyces cerevisiae strains obtained from sugarcane juice fermentations and their impact cachaça production. Appl. Environ. Microbiol. 74, 693-701.

Powell, C.D., Quain, D.E., Smart, K.A., 2003. The impact of brewing yeast cell age on fermentation performance, attenuation and flocculation. FEMS Yeast Res. 3, 149-157.

Querol, A., Bond, U., 2009. The complex and dynamic genomes of industrial yeasts. FEMS Microbiol. Lett. 293, 1-10.

Rosenberg, M., Gutnick, D., Rosenberg, E., 1980. Adherence of bacteria to hydrocarbons: a simple method for measuring cell-surface hydrophobicity. FEMS Microbiol. Lett. 9, 29-33.

Soares, E.V., 2010. Flocculation in Saccharomyces cerevisiae: a review. J. Appl. Microbiol. $110,1-18$.

Souza, A.P.G., Vicente, M.A., Klein, R.C., Fietto, L.G., Coutrim, M.X., Afonso, R.J.C.F., Araújo, L.D., Silva, P.H.A., Bouillet, L.E.M., Castro, I.M., Brandão, R.L., 2012. Strategies to select yeast starters cultures for production of flavor compounds in cachaça fermentations. Antonie Van Leeuwenhoek 101, 379-392.

Stratford, M., 1989. Yeast flocculation: calcium specificity. Yeast 5, 487-496.

Stratford, M., Assinder, S., 1991. Yeast flocculation: Flo1 and NewFlo phenotypes and receptor structure. Yeast 7, 559-574.

Teunissen, A.W., Steensma, H.Y., 1995. Review: the dominant flocculation genes of Saccharomyces cerevisiae constitute a new subtelomeric gene family. Yeast 11 , 1001-1013.

Vallejo, J.A., Sánchez-Pérez, A., Martínez, J.P., Villa, T.G., 2013. Cell aggregations in yeasts and their applications. Appl. Microbiol. Biotechnol. 97, 2305-2318.

Van Holle, A., Machado, M.D., Soares, E.V., 2012. Flocculation in ale brewing strains of Saccharomyces cerevisiae: re-evaluation of the role of cell surface charge and hydrophobicity. Appl. Microbiol. Biotechnol. 93, 1221-1229. 
Van Mulders, S.E., Christianen, E., Saerens, S.M.G., Daenen, L., Verbelen, P.J., Willaert, R, Verstrepen, K.J., Delvaux, F.R., 2009. Phenotypic diversity of Flo protein familymeditated adhesion in Saccharomyces cerevisiae. FEMS Yeast Res. 9, 178-190.

Van Mulders, S.E., Ghequire, M., Daenen, L., Verbelen, P.J., Verstrepen, K.J., Delvaux, F.R. 2010. Flocculation gene variability in industrial brewer's yeast strains. Appl. Microbiol. Biotechnol. 88, 1321-1331.

Veelders, M., Brückner, S., Ott, D., Unverzagt, C., Mösch, H.U., Essen, L.O., 2010. Structural basis of flocculin-mediated social behavior in yeast. Proc. Natl. Acad. Sci. U. S. A. 107, 22511-22516.

Verstrepen, K.J., Klis, F.M., 2006. Flocculation, adhesion and biofilm formation in yeasts. Mol. Microbiol. 60, 5-15.

Verstrepen, K.J., Derdelinckx, G., Verachtert, H., 2003. Yeast flocculation: what brewers should know. Appl. Microbiol. Biotechnol. 61, 197-205.
Verstrepen, K.J., Jansen, A., Lewitter, F., Fink, G.R., 2005. Intragenic tandem repeats generate functional variability. Nat. Genet. 37, 986-990.

Vicente, M.A., Fietto, L.G., Castro, I.M., Santos, A.N.G., Coutrim, M.X., Brandão, R.L., 2006 Isolation of Saccharomyces cerevisiae strains producing higher levels of flavoring compounds for production of cachaça, the Brazilian sugarcane spirit. Int. J. Food Microbiol. 108, 51-59.

Wilkening, S., Lin, G., Fritsch, E.S., Tekkedil, M.M., Anders, S., Kuehn, R., Nguyen, M., Aiyar R.S., Proctor, M., Sakhanenko, N.A., Galas, D.J., Gagneur, J., Deutschbauer, A Steinmetz, L.M., 2014. An evaluation of high-throughput approaches to QTL mapping in S. cerevisiae. Genetics http://dx.doi.org/10.1534/genetics.113.16029. 